\title{
Evolution of an extreme Pyrocumulonimbus-driven wildfire event in Tasmania, Australia
}

\section{Supplements}

S1 Atmospheric profile during the fire

\section{S1.1 BARRA soundings (aerological diagrams)}

In the BARRA pseudo-soundings on 4 January, the atmosphere was unstable, as evidenced by a sharp decrease in air temperature with height through the troposphere (Figs. S1a-b). The tropopause (often evident as a strong inversion) was not clearly defined, at least to approximately $200 \mathrm{hPa}(11.7 \mathrm{~km})$, thus contributing to the vertical development of the pyroCb. It is worth noting that the mid- to upper-level moisture in the figures is higher, suggesting cloud formation near $400 \mathrm{hPa}(7.1 \mathrm{~km})$, consistent with background cloud evident in Fig. 1. By contrast, the sounding at a similar time (15:00) on 9 January (when daily C-Haines was low during the fire period, Fig. S5) shows a temperature inversion occurring at around $850 \mathrm{hPa}(1.3 \mathrm{~km})$, with the air immediately above that level being moderately dry and stable (Fig. S1c).

15 


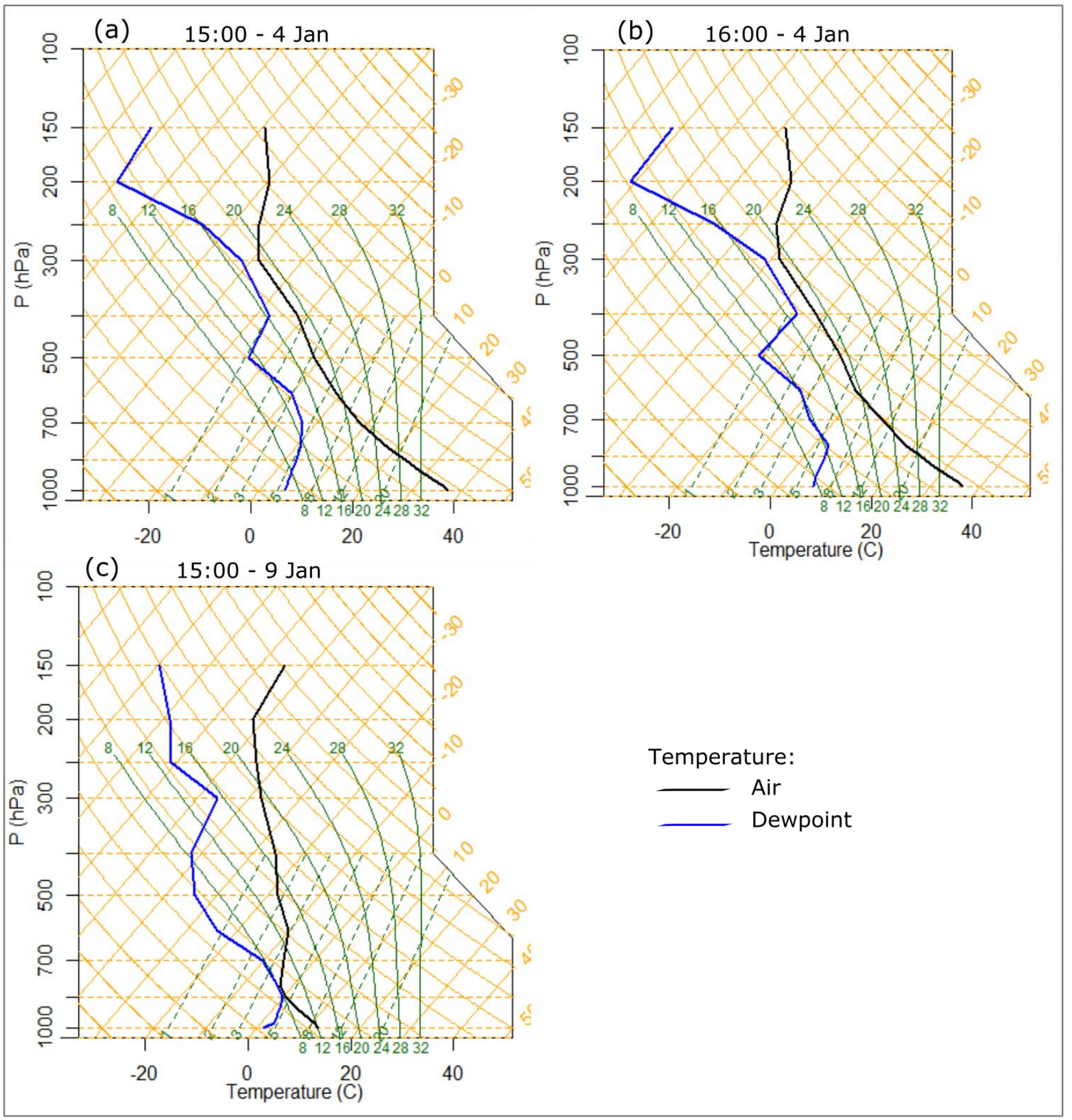

Fig. S1: BARRA soundings for Hobart Airport on 4 and 9 January 2013 representing period of highest and lowest C-Haines 25 respectively during the early days of the fire. $\mathrm{P}$ is atmospheric pressure in $\mathrm{hPa}$. (a-b) Sounding at 15:00 and 16:00 on $4 \mathrm{January}$ during rapid plume growth and pyroCb development, and (c) sounding at 15:00 on 9 January when smoke plume was not visible on the weather radar. 


\section{S1.2 Temperature lapse rate at lower atmosphere}

30 Figure $\mathrm{S} 2$ shows a time series of temperature lapse rate calculated from BARRA gridded air temperature at the 850 and 500 hPa pressure levels (or 1.3-5.5 km height) for January 2013 at Hobart Airport. The 850-500 hPa lapse rate gives an indication of the (in)stability of the lower half of the troposphere. In Fig. S2, LR was highest at the start of the fire, peaking at $8.6^{\circ} \mathrm{C} \mathrm{km}^{-}$ ${ }^{1}$ at 15:00 LT on 4 January 2013. LR> 7.5 ${ }^{\circ} \mathrm{Cm}^{-1}$ is considered as very unstable (Peterson et al., 2014) while LR of 6-7.5 ${ }^{\circ} \mathrm{C}$ $\mathrm{km}^{-1}$ is conditionally unstable, depending on the saturation level of the air. For saturated air parcels, $>6{ }^{\circ} \mathrm{C} \mathrm{km}^{-1}$ is unstable

35 while for dry parcels, $6-7.5^{\circ} \mathrm{C} \mathrm{km}^{-1}$ is stable. Convection is likely to be severe when the LR is above $7.5^{\circ} \mathrm{C} \mathrm{km}^{-1}$. Under such conditions, there is a likelihood of strong updrafts, thunderstorms and convective downdrafts, subsequently increasing the severity of fire weather, and ultimately fire behaviour when surface conditions are elevated. Values of LR $<6$ are generally stable. In Fig. S2, beyond 4 January, the atmosphere fluctuated between stable and conditionally unstable (from 5-31 January), with the afternoon (15:00) and night-time (21:00) having higher lapse rates than in the morning (09:00) for most days, as is typically the case.

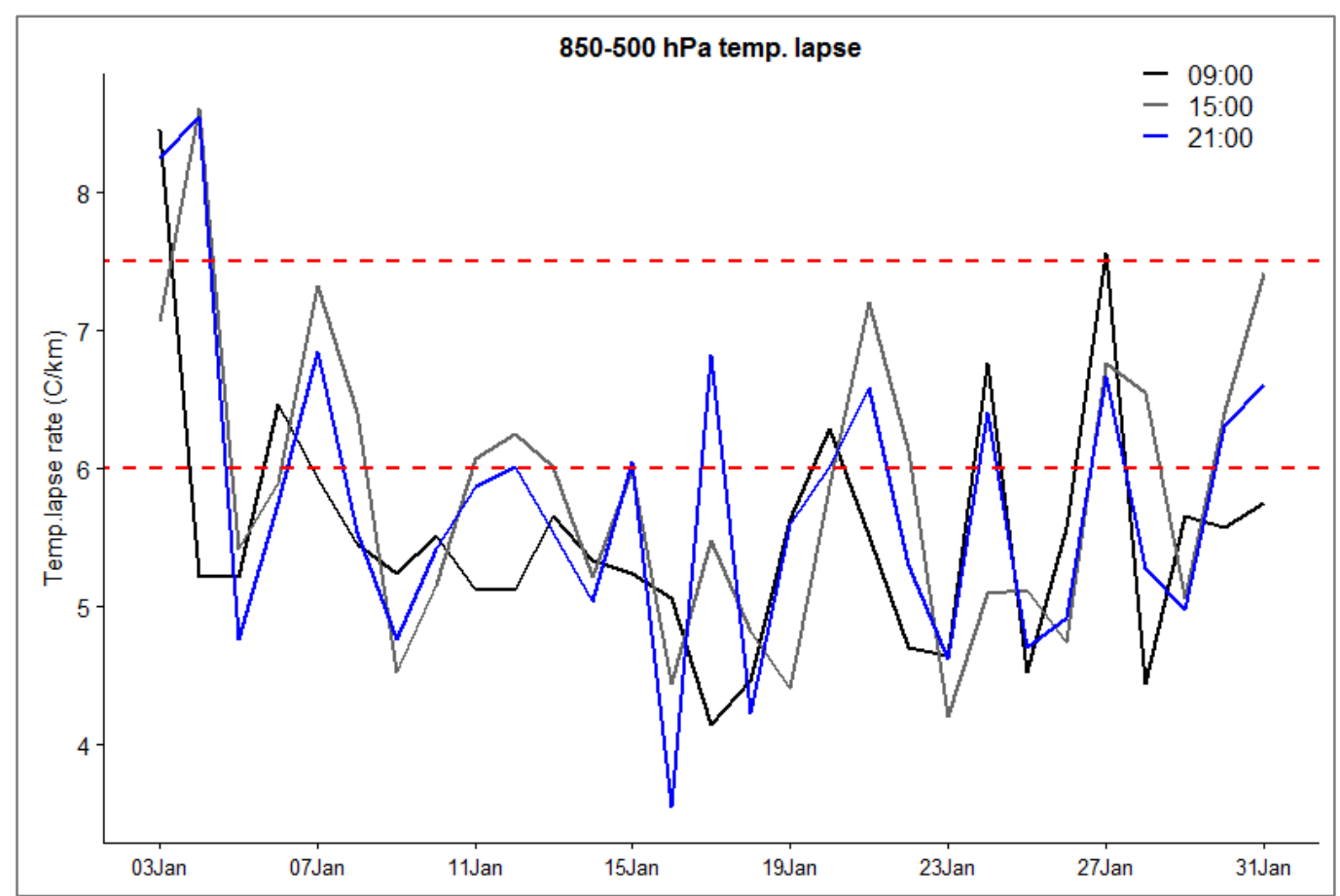

Fig. S2: Time series of temperature lapse rate between the 850-500 hPa levels for 09:00, 15:00 and 21:00 LT in January 2013 at the Hobart Airport. 
S2 Temporal smoke/pyroCb dynamics in 3D and 2D in Vorticity-driven Lateral Spread (VLS) prone areas

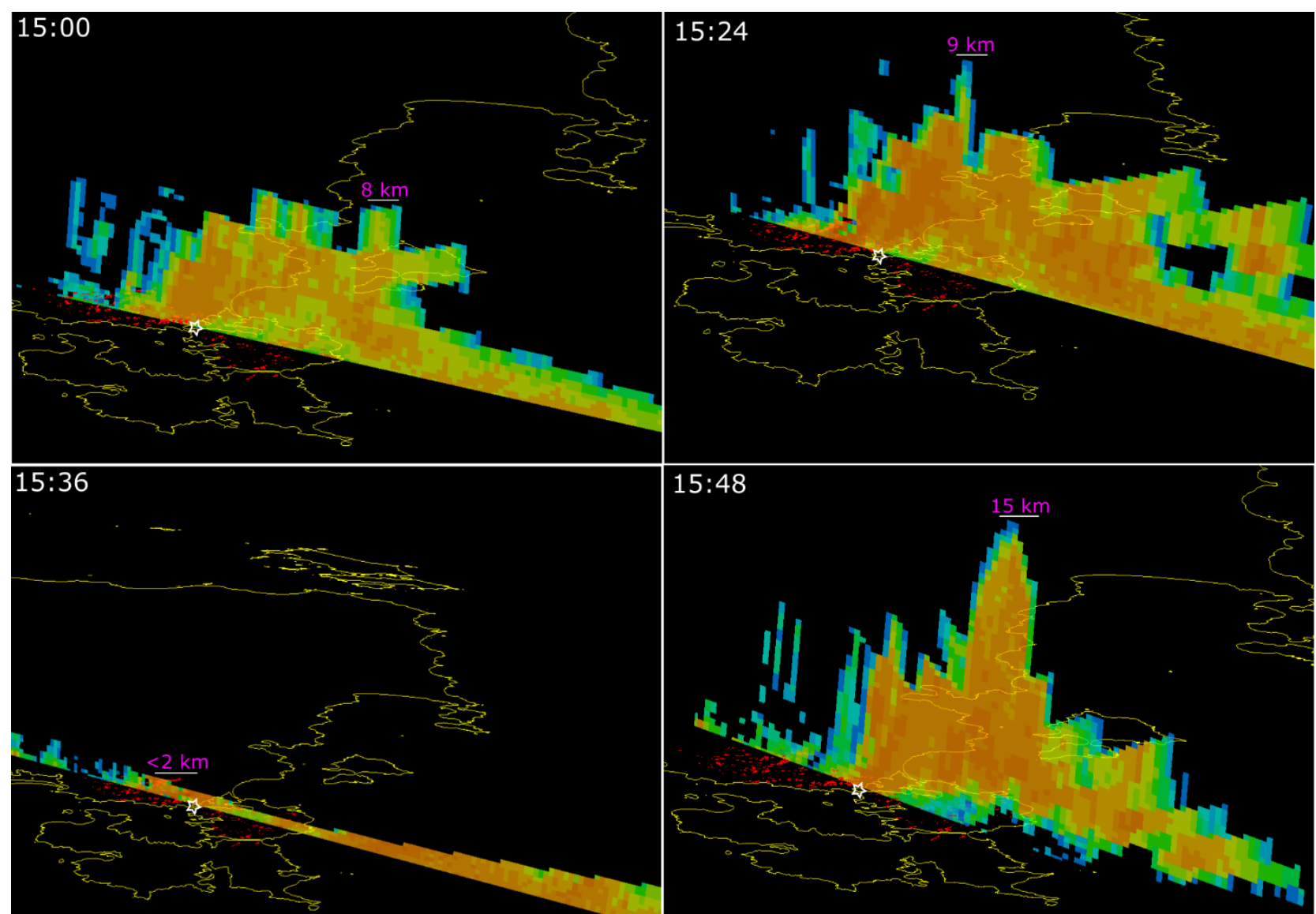

Fig. S3: Areas prone to vorticity-driven lateral spread (VLS, in red) overlaid with a 3D rendering of the vertical cross-section of plumes from the radar reflectivity for specific times during peak fire behaviour. The orange colour represents the most intense parts of the pyroCb. Dunalley township is represented by a white star. A malfunction in radar at 15:36 resulted in plume information to be only available at the lowest elevation angle of the radar scan (out of 14 levels). 


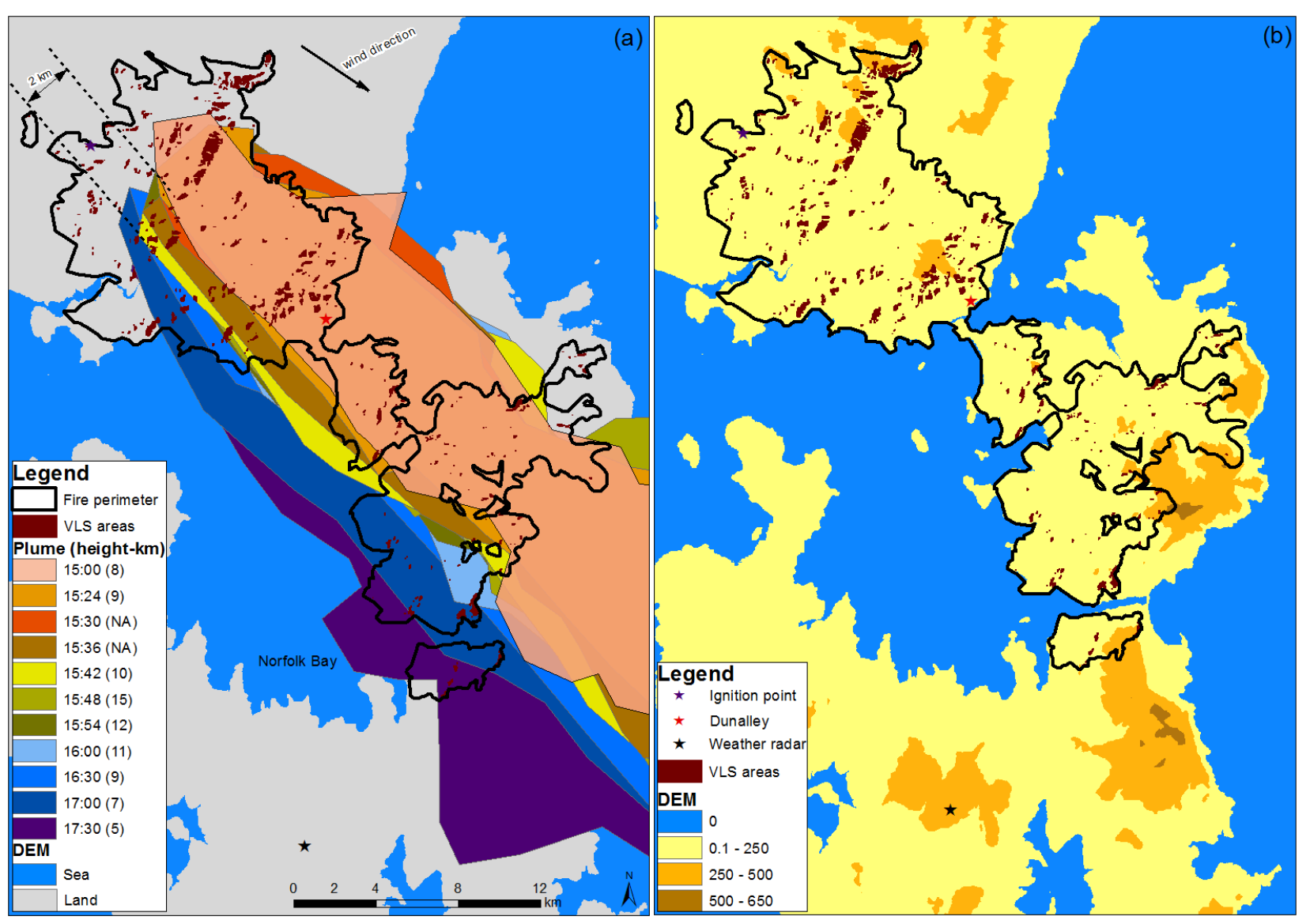

Fig. S4: A map of VLS-prone areas within the Forcett-Dunalley fireground overlaid with smoke plume progression and DEM/contours during the period (15:00-17:30 on 4 January) that includes peak fire behaviour. The dashed lines in panel (a) represent a rapid southwest $(2 \mathrm{~km})$ expansion of the upwind edge of the plume perpendicular to the prevailing northwest winds (before maximum plume height was attained). 


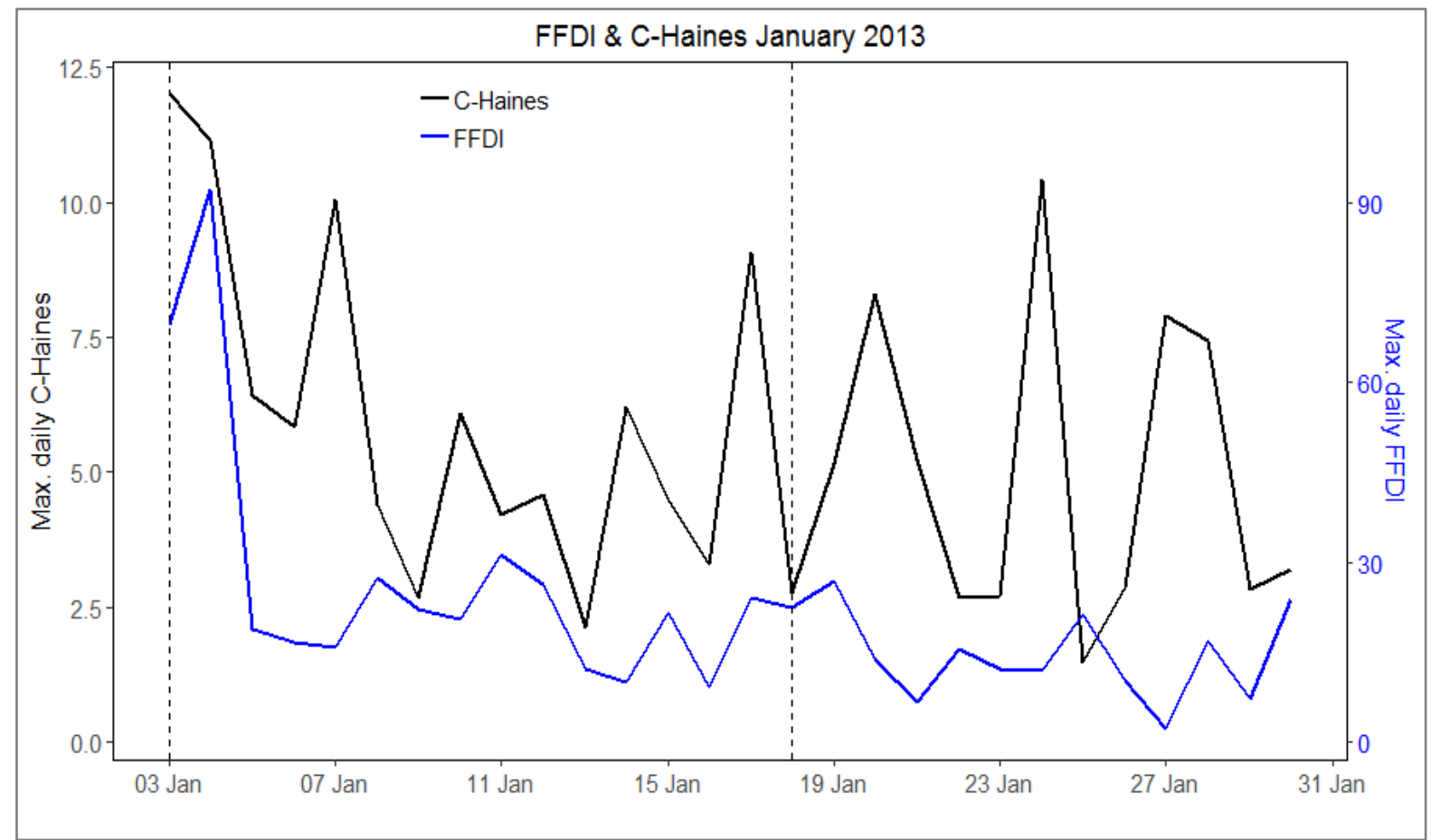

Fig. S5: Time series of daily maximum FFDI (calculated from 30-min weather data: temperature, relative humidity, wind 65 speed and soil moisture at Hobart Airport AWS) and daily maximum C-Haines (calculated from gridded BARRA model for Hobart Airport) in January 2013. Black vertical lines represent the start and end dates of the Forcett-Dunalley fire. 
S4 Time series of elevated fire weather and area burnt per fire management area (FMA) in Tasmania

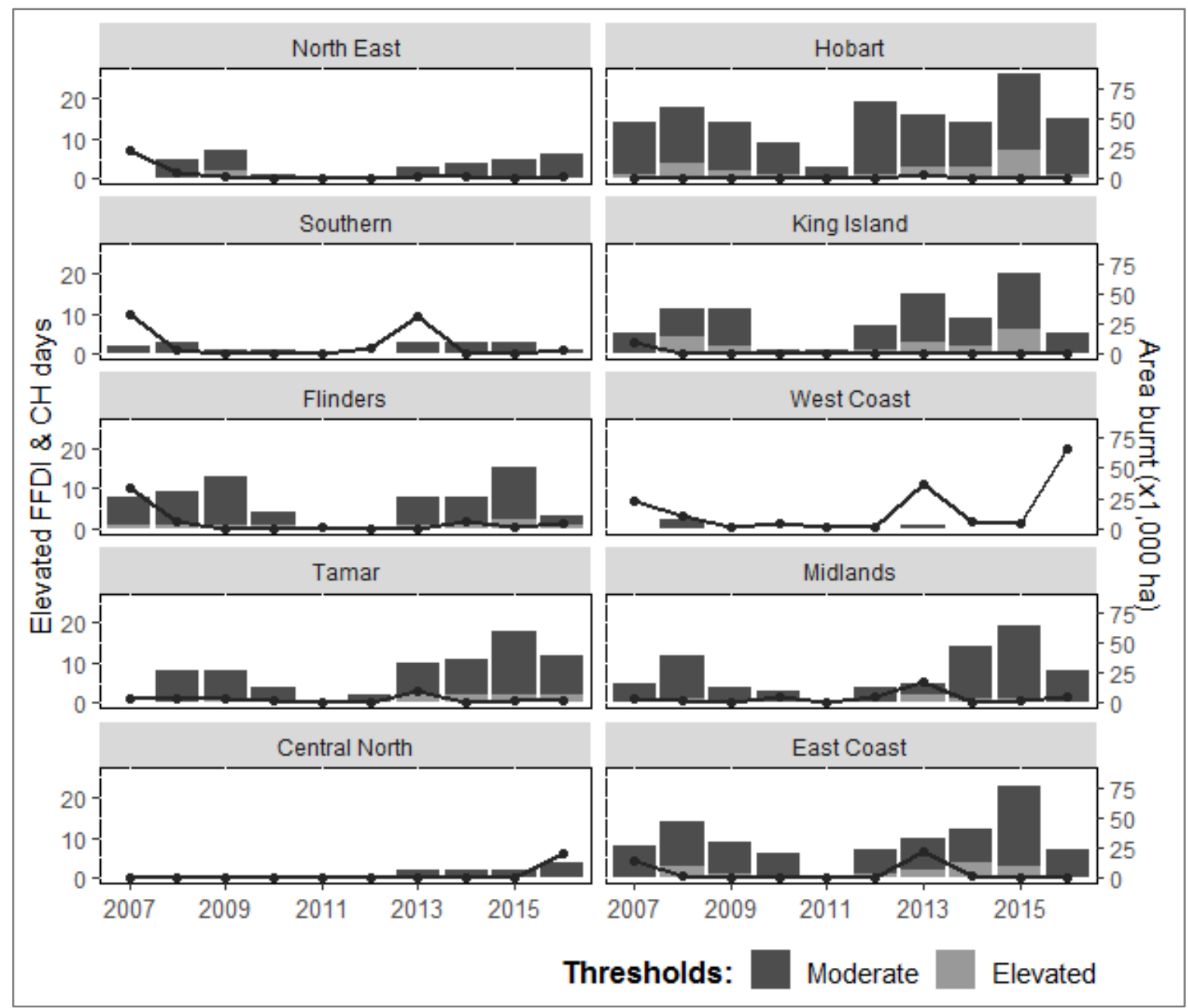

70 Fig. S6: Interannual variation of elevated fire weather days and area burnt in each fire management region in Tasmania. The bar graph represents number of days annually with elevated regional means of daily FFDI and C-Haines exceeding the following thresholds (FFDI $>15 \&$ C-Haines >7; and FFDI $>25 \&$ C-Haines $>9$ ). The line graph represents annual area burnt by wildfires irrespective of the ignition source. 
S5 Likely pyroCb pathway during the period of violent pyroconvection in Forcett-Dunalley fire

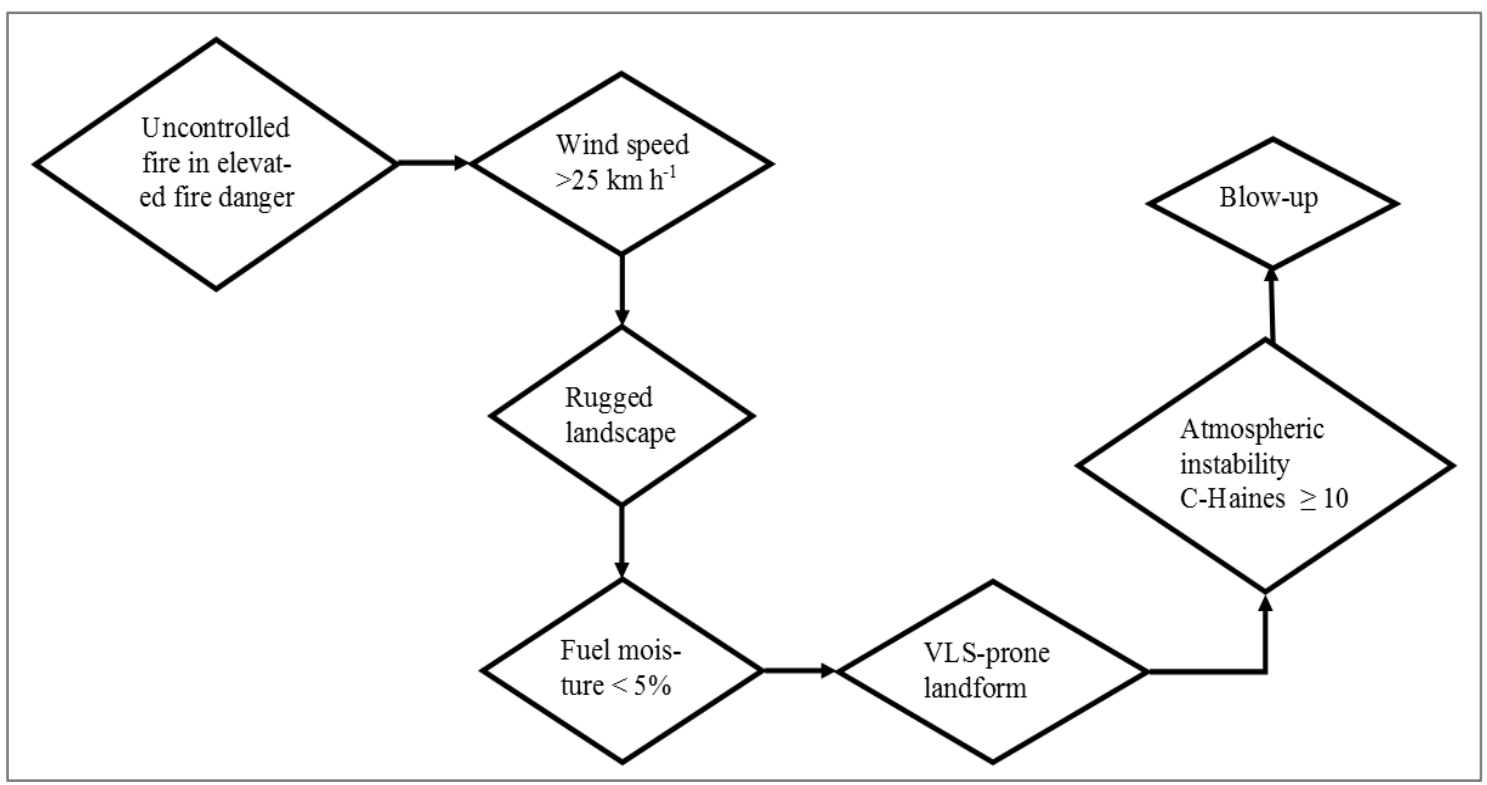

Fig. S7: Blow-Up Fire Outlook (BUFO) model pathway for parts of the Forcett-Dunalley fire during the period of violent pyroconvection on 4 January 2013, adapted from McRae et al. (2018). 